\title{
DO SUBJETIVO-LIBERAL AO OBJETIVO-SOCIAL: A BUSCA PELA EFETIVAÇÃO DO DIREITO FUNDAMENTAL AO MEIO AMBIENTE DE TRABALHO SEGURO
}

\author{
FROM THE LIBERAL-SUBJECTIVE TO THE SOCIAL- OBJECTIVE: THE PURSUIT \\ OF THE EFFECTIVENESS OF THE FUNDAMENTAL RIGHT TO A SAFE \\ WORKING ENVIRONMENT
}

\author{
Paulo Henrique Tavares da Silva \\ Centro Universitário de João Pessoa - UNIPÊ - João Pessoa - Paraíba - Brasil \\ Juliana Coelho Tavares da Silva \\ Universidade Federal da Paraíba -UFPB - João Pessoa - Paraíba - Brasil
}

\begin{abstract}
RESUMO: O direito de reparação do empregado por acidentes de trabalho, na sua modalidade subjetiva, encontra-se previsto no artigo $7^{\circ}$, inciso XXVIII, da Constituição Federal e está intrinsecamente relacionado com o direito a um meio ambiente de trabalho seguro, posto que atrelado à falta de cuidado patronal no cumprimento de normas de segurança, higiene ou saúde de seus empregados. $\mathrm{O}$ Código Civil de 2002 traçou novos rumos para a responsabilidade civil ao delinear a responsabilidade objetiva, à luz da teoria do risco criado. A hipótese que demonstramos é a de que hoje vivenciamos uma revolução no trato da natureza da responsabilidade civil do empregador, com a inversão da prioridade entre a espécie constitucionalmente prevista de caráter subjetivo e a responsabilidade objetiva. Para tanto, apresentamos julgados do Tribunal Superior do Trabalho e de Tribunais Regionais do Trabalho além da pesquisa bibliográfica. Concluiu-se pela necessidade de emprestar um sentido restritivo a expressão "atividade normalmente desenvolvida" com vistas à incidência da teoria do risco criado, sob pena de implantarmos custos excessivos à exploração econômica, o que, por outro lado, não pode ser feito situando-o tão só naquilo que seria o pertencimento econômico da empresa, para que se garanta a proteção ao direito do empregado a um ambiente de trabalho seguro.
\end{abstract}

PALAVRAS-CHAVE: Direito fundamental. Meio ambiente de trabalho seguro. Responsabilidade civil. Teoria do risco criado.

ABSTRACT: The employee's right to a compensation for work accidents in its subjective form is provided in Article 7, clause XXVIII, of the Federal Constitution and it is intrinsically related to the right to a safe working environment, since it is linked to a employer lack of care in compliance with standards of safety, hygiene and health of their employees. The Civil Code of 2002 has outlined new directions for civil liability when delineating the objective liability in light of the theory of created risk. The hypothesis that is demonstrated is that today we experience a revolution in dealing with the nature of the employer civil liability, with the reversal of the priority between the constitutionally subjective species and the objective liability. Therefore, it is presented decisions of the Superior Labor Court and Regional Labour Courts in

Revista do Direito da UNISC, Santa Cruz do Sul, v.1, n. 45, p. 104-127, jan. - abri. 2015. 
addition to a bibliographical research. It was concluded that it is necessary to give a restrictive meaning to the expression "normally developed activity" in regard to the incidence of the theory of created risk, under the penalty of having excessive economic exploitation costs, what on the other hand, cannot be done by placing this meaning only in what would be the economic belonging of the company in order to guarantee the protection of the employee's right to a safe working environment.

KEYWORDS: Fundamental right. Safe working environment. Civil liability. Theory of created risk.

\section{CONSIDERAÇÕES INICIAIS}

Trilhar o caminho historicamente percorrido quando se trata da responsabilidade civil, especialmente a partir do século XVIII, também é descrever a evolução do direito dentro da ambiência do capitalismo. $E$ isso ainda é mais marcante quando se enfrenta as mutações que esse instituto enfrentou em relação à responsabilização dos empregadores quanto aos danos advindos aos seus empregados.

Portanto, insere-se nosso estudo da responsabilidade civil como decorrência de um contrato de trabalho, figura jurídica inconcebível noutro contexto que aquele do capital, relação jurídica que necessita ter como pressuposto a transformação da força de trabalho numa mercadoria. De outro lado, também daí decorre a condição de se atribuir ao empregador a livre inciativa em compor o trabalho vivo com o maquinário, visando otimizar a produção de bens e serviços, liberdade que atrai, em contrapartida, a assunção dos riscos da atividade econômica, elemento que no direito do trabalho brasileiro passou a ostentar elemento essencial para a definição do que seria mesmo a figura do empregador (CLT, art. $2^{\circ}$.).

Evidentemente, essa transferência dos riscos da atividade econômica se contrapõe tantas vezes à realidade, haja vista que o encerramento da atividade econômica desenvolvida pelo empregador é pena capital para o empregado, despossuído de outros meios de subsistência além da própria força de trabalho. Trata-se, com efeito, de delicada equação, ajustada ao longo do tempo não apenas pelos legisladores, como também na prática dos tribunais, reveladora da evolução do direito e cenário do nosso estudo.

Gradualmente, a ideia de risco foi sendo potencializada, hoje ocupando a centralidade no contexto da mundialização do capital, e não poderia ser diferente o

Revista do Direito da UNISC, Santa Cruz do Sul, v.1, n. 45, p. 104-127, jan. - abri. 2015. 
raciocínio quando aplicado às relações trabalhistas. Dessa forma, percebe-se o crescimento dos riscos a que os laboristas estão submetidos, especialmente no que concerne aos acidentes de trabalho, sendo alguns quase inevitáveis ou até mesmo previsíveis. Cada vez mais é necessário prezar pela solidariedade, proteção e reparação dos prejuízos sofridos, devendo estar o empregador atento aos novos rumos da sua responsabilidade civil.

No âmbito da proteção jurídica do trabalho, o direito de reparação do empregado por acidentes de trabalho encontra-se previsto no artigo $7^{\circ}$, inciso XXVIII, da Constituição Federal, na forma de benefício previdenciário, sem que haja prejuízo da indenização por parte do empregador, quando este incorrer em dolo ou em culpa, reflexo da aplicação da responsabilidade subjetiva.

O Código Civil de 2002 traçou novos rumos para a responsabilidade civil, e a partir de princípios e tipos, delineou a teoria do risco e possibilidade de responsabilização sem culpa. O novo cenário de aplicação de responsabilidade objetiva ao empregador, aberto pelo diploma civilista, foi, e continua sendo razão de celeuma quando do julgamento de reclamações nos Tribunais do Trabalho. Isso porque o parágrafo único do artigo 927 possui textura aberta e, consequentemente, alto grau de indeterminação ao aduzir que haverá obrigação de reparar o dano, independentemente de culpa, quando a atividade normalmente desenvolvida pelo autor do dano implicar, por sua natureza, risco para os direitos de outrem.

A hipótese que pretendemos demonstrar é a de que hoje estamos vivenciando uma autêntica revolução no trato da natureza da responsabilidade civil do empregador, com a inversão da prioridade que se dava à espécie subjetiva e ocupação de espaços cada vez maiores à responsabilidade objetiva, em decorrência justamente da disseminação dos riscos nas atividades econômicas que, por princípio contratual, devem ser assumidos pelos empregadores. E caminho para tal transformação é justamente o entendimento que as cortes trabalhistas vêm abraçando daquilo que significa "atividade de risco". Para tanto, apresentaremos julgados do Tribunal Superior do Trabalho e de Tribunais Regionais que ilustram nossa tese, além do respaldo que nos dá a pesquisa bibliográfica, desde os realistas estadunidenses, passando por Hart e sua concepção da textura aberta das normas, que nos outorgam pensar dessa forma.

Revista do Direito da UNISC, Santa Cruz do Sul, v.1, n. 45, p. 104-127, jan. - abri. 2015. 
Se o conceito de "atividade de risco" é protagonista nessa mutação jurisprudencial, ele também é elemento-chave para tracejar os limites entre o uso de uma responsabilização quase que automática (de natureza objetiva) para aquela a demandar maior atividade probante (de corte subjetivo), devendo a ele ser acoplado, como parâmetro interpretativo, razões extrassistêmicas de natureza econômicas e estratégicas quando se trata da redução dos custos sociais decorrentes da atividade produtiva.

\section{A INERÊNCIA DA NOÇÃO DE RISCOS DA ATIVIDADE ECONOMICA NO CONCEITO LEGAL DE EMPREGADOR}

A Consolidação das Leis do Trabalho, logo em seu artigo $2^{\circ}$, "caput", conceitua empregador como sendo "a empresa, individual ou coletiva, que, assumindo os riscos da atividade econômica, admite assalaria e dirige a prestação pessoal de serviços". Numa primeira leitura, já resta evidenciado que o legislador da década de 1940 fez uso de uma categoria estranha ao direito vigente daquela época, a noção de "empresa", posto que o Código Civil de 1916 continha tão-só a distinção entre pessoas físicas e jurídicas. Essa contradição ainda era mais ressaltada quando no primeiro parágrafo daquele artigo criava-se a figura do "empregador por equiparação", agregando ali aquelas pessoas e entidades que não exerciam atividade lucrativa, muito embora fizessem uso de empregados. Essa divergência não passou despercebida por Octávio Bueno Magano, tendo ele apontado que a ideia da assunção dos riscos da atividade econômica não era essencial ao conceito de empregador, mesmo porque, pessoas que não a exercem enquadram-se naquele tipo, inexistindo, inclusive, qualquer razão lógica à terminologia "empregador do equiparação" (1993, p. 60).

Decerto que a vinculação do termo risco ao de atividade econômica nos conduz a determinados problemas de difícil solução, ligados até os limites da assunção dessa responsabilidade: que riscos estou assumindo, há alguma limitação, podem ser mitigados de alguma forma? Diante de tais perplexidades, passou a ser conveniente, por exemplo, eliminar o elemento atividade econômica como critério marcante para o conceito de empregador, como o faz Delgado (2003 p. 390), ao afirmar:

Revista do Direito da UNISC, Santa Cruz do Sul, v.1, n. 45, p. 104-127, jan. - abri. 2015. 
$\mathrm{Na}$ verdade, o que ocorre é que a letra do enunciado celetista (risco da atividade econômica) não corresponde à específica intenção da norma, nem à plena noção jurídica dos riscos que pertinem à posição jurídica do empregador no âmbito da relação de emprego. Ao se referir à idéia de riscos, o que pretende a ordem justrabalhista é traduzir a idéia de responsabilização do empregador pelos custos e resultados do trabalho prestado, além da responsabilização pela sorte de seu próprio empreendimento (se se tratar de empregador vinculado a atividade econômica).

Ou seja, por essa visão, o que se compartilha entre os empregadores, para fins conceituais, são os custos e resultados do trabalho que se assalaria, acrescendo-se, apenas na órbita subjetiva de cada empresário, os demais riscos da atividade econômica ligados à busca do lucro, posição que se nivela com aquela anterior, afastando a noção de risco do conceito, digamos, puro, de empregador ${ }^{1}$.

De fato, naquele dispositivo legal, em parte inicial, além da confusão conceitual entre pessoa e instituição, associou-se ao conceito de empregador um atributo oriundo da busca pelo lucro, que é o risco. Mas igualmente aquele texto legal deixa evidenciar que os poderes do empregador de direção da prestação de serviços, decorrem, radicalmente, do fato de ser ela, "a empresa", que assalaria o empregado, aliada ao fato de ser dela os riscos dessa atividade, como que dotandoo de poder em função de enfrentar possíveis intempéries do mercado.

Por tal razão a consolidação, considerando o contexto histórico da sua gênese, feita para priorizar a regulação do capitalismo industrial em franco desenvolvimento no país, preferiu colocar num plano secundário aqueles empregadores e determinados tipos de empregados (a exemplo dos domésticos e rurícolas) que não se relacionavam diretamente com o contrato-padrão que ali estava sendo construído. Pode-se até afirmar que essa dicotomia referente à atividade econômica somente vai ter seu decretado com a Constituição Federal de 1988, que mesmo assim preferiu dar tratamento diferenciado aos empregados domésticos, distinção solucionada com a Emenda Constitucional 72/13. Entretanto, o fato de todos os empregadores terem sido nivelados no plano normativo através

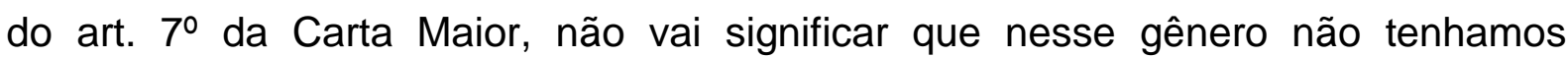

\footnotetext{
${ }^{1}$ No mesmo sentido, cite-se SÜSSEKIND et al, para quem "desde que haja uma atividade econômica (produção de bens e serviços), na qual se utiliza a força do trabalho alheia como fator de produção, existe a figura do empregador" (1996, p. 291). Aqui se amplia a noção de atividade econômica, albergando inclusive os empregadores ditos, sem fins lucrativos.
}

Revista do Direito da UNISC, Santa Cruz do Sul, v.1, n. 45, p. 104-127, jan. - abri. 2015. 
espécies, fato que vai nos interessar quando se trata da extensão da responsabilidade objetiva dos empregadores.

O Código Civil de 2002 apresenta o conceito de empresário como sendo aquele "que exerce profissionalmente atividade econômica organizada para a produção ou circulação de bens ou de serviços" (art. 966) e, sendo o contrato de sociedade aquele em que as pessoas congregam esforços para o exercício da atividade econômica (art. 981), obviamente em remissão ao conceito anterior individualizado. Nada se fala de risco. Nem precisava.

Note-se que o Código Civil também nos apresenta o conceito de associação em seu art. 53, sendo o traço diferencial com a sociedade empresária justamente o exercício da atividade econômica, sendo esta, como bem esclarece Campinho, definida pela busca do lucro a ser partilhado entre seus integrantes. E desde a época do capitalismo mercantil, com o movimento das grandes navegações, ter ou não lucro é uma questão de assumir riscos (2009, p. 36). Logo, o advento de um novo sistema normativo paralelo e complementar ao direito do trabalho nacional, fez eliminar as objeções anteriormente feitas acerca da presença do risco como elemento nuclear aqueles empregadores que exercem típica atividade empresária, seja individual ou coletiva.

Conceber que há dois tipos de empregadores, sendo um deles atrelado diretamente à atividade econômica se revela importante quando estamos no terreno da fixação da natureza da responsabilidade em casos de danos à integridade física dos empregados. Isto porque a evolução do conceito da modalidade objetiva está imbricada com o desenvolvimento da noção de compartilhamento de riscos na sociedade industrial, como veremos a seguir, daí, seu habitat natural seria justamente aquele onde prevalecem as relações ligadas às forças produtivas e aos poderes conferidos aos empregadores em tal cenário.

Logo, se existe uma tendência à disseminação da responsabilidade objetiva, liga-se ela precipuamente aqueles empregadores que assumem, efetivamente, os riscos da atividade econômica, posicionamento diverso quando estamos diante de um empregador que não se relaciona com a busca pela obtenção do lucro, inclusive os entes estatais. O poder diretivo do empregador nessa área é sobremaneira gerador de maior interesse porque na exploração de determinada atividade no mercado, caberá ao comando empresarial promover modificações no pertencimento 
econômico da empresa, opção passível de gerar alterações unilaterais lesivas aos trabalhadores, criando um ambiente de risco que antes não acontecia. Não é preciso ir muito longe para testificar os efeitos dessa tomada de posição, haja vista que o Código Civil, ao tratar da configuração do ato ilícito, em seu art. 187, elenca como fato gerado a extrapolação dos limites impostos pelo fim econômico ou social daqueles direitos que são conferidos a um titular pela ordem jurídica. Mais adiante, quando se fala daquilo que é gerado pela atividade econômica das empresas, consagra aquele diploma legal a responsabilidade objetiva dos empresários individuais e das empresas pelos danos causados pelos produtos que se põem em circulação (art. 931, CCB).

\section{TRAÇANDO O CAMINHO DO SUBJETIVO-LIBERAL AO OBJETIVO-} SOCIAL

Há dois caminhos para a evolução do direito: via legislativa ou a prática dos tribunais. Daqui em diante pretendemos demonstrar como foi o processo gradual que levou ao estabelecimento dos dois tipos clássicos de responsabilidade e de como atualmente, graças à disseminação dos riscos advindos da exploração econômica generalizada de vários setores da vida societária até então inexplorados, foi-se impondo o tipo objetivo, cuja prova judicial é sobremaneira mais simplificada para a vítima. Aqui voltamos nossa atenção ao desenvolvimento das normas tratando do tema.

O termo responsabilidade pode ser compreendido como o dever de assumir as consequências provenientes de nossos atos. Em via de regra, a transgressão de um direito, ou seja, atividades que geram algum tipo de prejuízo, resultam no dever de indenizar. O direito regula a responsabilização de dois modos: a responsabilidade civil, que será abordada neste estudo, e a penal. A responsabilização civil tem primordialmente a função de restaurar um equilíbrio patrimonial e moral violado, já que um dano não reparado é fonte de desequilíbrio social (VENOSA, 2005, p.14).

A concepção clássica e tradicional da teoria subjetiva da responsabilidade civil, está ligada à ideia de que para ser devida uma indenização a outrem, é necessário além dos requisitos da ação ou omissão voluntária, relação de causalidade ou nexo causal, dano e a comprovação de uma conduta dolosa, 
imprudente ou negligente, ou seja, da culpa do agente. Ela foi amplamente propagada pelos juristas da modernidade, tendo como pilares do seu desenvolvimento o ideário liberal e individualista do século XIX, que valorizava a autonomia privada.

Neste sentido é a opinião de Glaucia Rodrigues Torres de Oliveira Mello (2010, p.3):

A responsabilidade civil como concebida pelos juristas da
Modernidade tem indubitavelmente o seu cerne depositado na noção
de culpa. O sistema de ideais liberais e individualistas que
predominava à época da elaboração da concepção impunha um
sistema de responsabilização que deixasse largo espaço para a livre
atuação da vontade privada.
No séc. XIX, muitos juristas anunciavam a conhecida máxima
"nenhuma responsabilidade sem culpa", ou como resumia Rudolf
Von lhering "sem culpa, nenhuma reparação. A regra da culpa tem
seu lugar em decorrência desse individualismo liberal pregado neste
século, segundo o qual a liberdade de atuação individual só poderá
ser restringida pela imposição de responsabilidade por danos,
quando Ihe seja imputada uma conduta dolosa, imprudente ou
negligente, passível de reprovação.

Diante das rápidas mudanças sociais, econômicas e tecnológicas pós Revolução Industrial, percebeu-se que a teoria subjetiva não mais atendia aos anseios populares, tendo em vista que trazia para a vítima o ônus de demonstrar em juízo o conjunto probatório necessário para a responsabilização do autor do fato. Assim, a aferição da culpa como pré-requisito da responsabilização foi se tornando insuficiente para a efetivação do dever de reparação. Nos mostra Mello (2010, p.6) que em resposta às crescentes injustiças, surgiram alternativas à exemplo da adoção das presunções de culpa:

A adoção das presunções de culpa representava em verdade uma
solução intermediária para o problema, marcada principalmente
pelos valores de uma sociedade ainda fortemente impregnada pelas
concepções liberais burguesas, e que não queria abrir mão da culpa
como pressuposto da responsabilidade. Era unicamente o apego
formal à teoria da culpa que justificava a inclusão da culpa
presumida, cada vez mais absoluta, sob o manto da
responsabilidade subjetiva.

Outrossim, é necessário ressaltar que a aplicação da teoria subjetiva foi ainda mais questionada diante do grande número de acidentes de trabalho decorrentes do crescimento da indústria e da mecanização da produção. A Revolução Industrial facilitou o êxodo rural e acabou por levar milhares de pessoas a deixar o campo e

Revista do Direito da UNISC, Santa Cruz do Sul, v.1, n. 45, p. 104-127, jan. - abri. 2015. 
procurar os centros urbanos à procura de emprego e renda. Contudo, o grau de instrução e de treinamento desses operários era muito baixo, além das jornadas e condições de trabalhos desumanas a que estavam submetidos. A demonstração da culpa, portanto, "tornava-se verdadeira prova diabólica, diante da condição de vulnerabilidade do empregado, do parco conhecimento sobre o maquinário das fábricas ou ainda por conta do anonimato de certos acidentes dentro das fábricas" (MELLO, 2010, p.5)

Surgiu, então, a ideia de uma responsabilidade civil que não questionasse a existência ou o grau de culpa, fruto da substituição do patrimonialismo do século XIX, de caráter iluminista por uma visão de sociedade mais solidária, com a correlata valorização da dignidade do ser (PEDRO, 2011, p.69). Assim, ao final do século XIX, as concepções de risco e de garantia foram reforçadas, na busca de um fundamento para a responsabilidade objetiva e foi desenvolvida a teoria do risco.

Sob esse prisma, nos mostra Venosa (2005, p.25) que o cerne da noção da teoria do risco é o de que quem tira proveito do exercício de uma atividade responderá pelos danos que ela venha a causar, independente de culpa sua ou de prepostos:

\begin{abstract}
A teoria do risco aparece na história do Direito, portanto, com base no exercício de uma atividade, dentro da ideia de que quem exerce determinada atividade e tira proveito direito ou indireto dela, responde pelos danos que ela causar, independentemente de culpa sua ou de prepostos. O princípio da responsabilidade sem culpa ancora-se em um princípio de equidade: quem aufere os cômodos de uma situação deve também suportar os incômodos. O exercício de uma atividade que possa representar um risco, obriga por si só a indenizar os danos causados por ela.
\end{abstract}

Do princípio da teoria do risco surgiram diversas correntes ou modalidades, dentre as quais temos as teorias do risco-proveito, risco profissional, risco excepcional, risco criado e do risco integral. Sobre o tema, Sergio Cavalieri Filho (2005) expõe que no risco- proveito o fundamento é o de que quem aproveita os frutos da utilização de coisas ou atividades perigosas deve experimentar as consequências danosas dela decorrentes. Note-se que a teoria do risco criado pode ser considerada como uma ampliação do conceito de risco proveito, já que aumenta os encargos do agente, tendo em vista que não é necessário ser o dano correlato de um proveito ou vantagem.

Revista do Direito da UNISC, Santa Cruz do Sul, v.1, n. 45, p. 104-127, jan. - abri. 2015. 
Quanto ao risco profissional, o mesmo autor aponta como suporte doutrinário que o fato prejudicial é uma decorrência da profissão do lesado. É importante notar que ela foi especialmente desenvolvida para justificar a reparação dos acidentes ocorridos com os empregados no trabalho ou por ocasião dele. Para a teoria do risco excepcional, a reparação seria devida sempre que o evento danoso fosse consequência de um risco que escapasse a atividade comum do prejudicado, ainda que alheio a atividade normalmente desempenhada pelo mesmo. Por fim, Cavalieri (2005) evidencia a teoria do risco integral, mostrando ser esta uma teoria extremada, posto que destinada a justificar a responsabilização civil até nos casos em que não restar comprovado o nexo causal.

No Brasil, o núcleo central da responsabilidade civil está previsto, especialmente, nos artigos 186, 187 e 927 do Código Civil de 2002, abaixo transcritos:

Art.186. Aquele que, por ação ou omissão voluntaria, negligencia ou imprudência, violar direito e causar dano a outrem, ainda que exclusivamente moral, comete ato ilícito.

Art. 187. Também comete ato ilícito o titular de um direito que, ao exercê-lo, excede manifestamente os limites impostos pelo seu fim econômico ou social, pela boa-fé ou pelos bons costumes.

Art. 927. Aquele que, por ato ilícito (arts. 186 e 187), causar dano a outrem, fica obrigado a repará-lo.

Parágrafo único. Haverá obrigação de reparar o dano, independentemente de culpa, nos casos especificados em lei, ou quando a atividade normalmente desenvolvida pelo autor do dano implicar, por sua natureza, risco para os direitos de outrem.

É importante evidenciar que muito embora o Código Civil de 2002, em seu artigo 186, tenha mantido a responsabilização subjetiva, também percebemos a aplicação da teoria objetiva da responsabilização civil, a partir de uma leitura sistemática do art. 187, em especial, com o art. 931 e no parágrafo único do artigo 927, este que será melhor analisado nos próximos tópicos deste artigo. Ademais, a responsabilidade objetiva também está presente no nosso ordenamento jurídico, em legislação especial, podendo ser citados o Decreto n. 2.681/12, que dispõe sobre as estradas de ferro; a Lei n. 7.565/86; O Código Brasileiro de Aeronáutica; o Decretolei n. 227/67; Código de Mineração; o Código de Defesa do Consumidor e o Código de Trânsito Brasileiro.

Revista do Direito da UNISC, Santa Cruz do Sul, v.1, n. 45, p. 104-127, jan. - abri. 2015. 


\section{APLICABILIDADE DA RESPONSABILIDADE CIVIL OBJETIVA NOS CASOS DE ACIDENTE DE TRABALHO}

Acerca da evolução do direito pela via judicial, lembra-nos Benjamin Natan Cardozo (2004, p.40):

Alguns casos existem, naturalmente, em só há um único caminho possível. São os casos em que a lei é rígida. Sobra-lhes em quantidade o que lhes falta em interesse. Outros casos apresentam uma verdadeira oportunidade para a escolha - não entre duas decisões, uma das quais pode ser considerada como quase absolutamente certa e a outra como quase absolutamente errada -, mas uma escolha de tal modo equilibrada que, uma vez anunciada, faz surgir uma nova concepção do que é direito e do que não é.

Naquilo pertinente à aplicação da responsabilidade objetiva no âmbito do direito do trabalho, poderíamos dizer o judiciário vem adotando tais escolhas, a partir da abertura que se criou nos textos legais.

Inicialmente, é importante ressaltarmos a abrangência do conceito de acidente de trabalho. O conceito legal de acidente do trabalho típico se encontra no artigo 19 da Lei $n^{\circ} 8.213 / 91$, sendo este o seu sentido estrito:

Acidente do trabalho é o que ocorre pelo exercício do trabalho a serviço da empresa ou pelo exercício do trabalho dos segurados referidos no inciso VII do artigo 11 desta Lei, provocando lesão corporal ou perturbação funcional que cause a morte ou a perda ou redução, permanente ou temporária, da capacidade para o trabalho.

No entanto, "o legislador não conseguiu formular um conceito de acidente do trabalho que abrangesse todas as hipóteses em que o exercício da atividade profissional pelo empregado gera incapacidade laborativa" (OLIVEIRA, 2005, p.35), isso porque a limitação pode surgir por fatores alheios ao conceito estrito de acidente de trabalho. Assim, acrescentou-se um sentido mais amplo, contemplando outras hipóteses que se equiparam ao acidente- tipo, à exemplo das doenças ocupacionais, acidentes in itinere, ou daquelas previstas no artigo 21 da Lei oo 8.213/91, que não estão diretamente relacionadas com a atividade profissional, havendo mero vinculo causal indireto:

Equiparam-se também ao acidente do trabalho, para os efeitos desta Lei $(. .$.

II- o acidente sofrido pelo segurado no local e no horário do trabalho, em consequência de:

Revista do Direito da UNISC, Santa Cruz do Sul, v.1, n. 45, p. 104-127, jan. - abri. 2015. 
a)Ato de agressão, sabotagem ou terrorismo praticado por terceiro ou companheiro de trabalho;

b) Ofensa física intencional, inclusive de terceiro, por motivo de disputa relacionada ao trabalho;

c) Ato de imprudência, de negligencia ou de imperícia de terceiro ou de companheiro de trabalho;

d) Ato de pessoa privada do uso da razão;

e) Desabamento, inundação, incêndio e outros casos fortuitos ou decorrentes de força maior. (...)

O dever de reparação nos casos de acidente de trabalho é norma constitucional, nos termos do artigo $7^{0}$, inciso XXVIII, que estabelece que são "direitos dos trabalhadores urbanos e rurais, além de outros que visem à melhoria de sua condição social: [...] seguro contra acidentes do trabalho, a cargo do empregador, sem excluir a indenização a que este está obrigado, quando incorrer em dolo ou culpa". Observa-se, então, que o dispositivo normativo prevê dois tipos de indenização, autônomas e cumuláveis: uma de direito civil comum e outra a ser custeada pela Previdência Social. Ou seja, a cobertura do INSS não exclui, nem se caracteriza como bis in idem, quando cabível, a responsabilidade civil do empregador, ainda que ele possua apenas culpa leve ou levíssima no infortúnio.

Sobre a responsabilidade subjetiva do empregador nos casos de acidente de trabalho, Sebastião Geraldo de Oliveira (2005, p.78) expõe:

A ocorrência do acidente ou doença proveniente do risco normal da atividade patronal não geral automaticamente o dever de indenizar, restando a vítima, nessa hipótese, apenas a cobertura do seguro de acidente do trabalho, conforme as normas da Previdência Social.

O substrato do dever de indenizar repousa no comportamento desidioso do patrão que atua descuidado do cumprimento das normas de segurança, higiene ou saúde do trabalhador, propiciando, pela sua incúria, a ocorrência do acidente ou doença ocupacional. Com isso, pode-se concluir que, a rigor, o acidente não surgiu do risco da atividade, mas originou-se da conduta culposa do empregador.

Não se pode olvidar que enquanto a reponsabilidade do empregador necessita da caracterização da culpa, posto que fundamentada na teoria subjetiva, a responsabilidade previdenciária se baseia na teoria objetiva do risco integral. Isto quer dizer que o INSS tem o dever de efetuar a indenização desde que reste comprovado a relação de emprego, o dano decorrente do acidente e que o mesmo ocorreu no trabalho ou por ocasião do mesmo (CAVALIERI FILHO, 2005, p.160). Acerca do assunto, nos alerta Sergio Cavalieri (2005, p.161):

Revista do Direito da UNISC, Santa Cruz do Sul, v.1, n. 45, p. 104-127, jan. - abri. 2015. 
Registre-se, ainda, que serve de fundamento para a indenização por acidente do trabalho, a teoria do risco integral, de sorte que nem mesmo as causas de exclusão do nexo causal- culpa exclusiva da vítima, fato de terceiro, caso fortuito ou força maior- afastam o direito do obreiro, desde que o evento tenha se dado no trabalho, ou em razão dele.

O Código Civil de 2002 trouxe inovações na aplicação da teoria objetiva, principalmente quando falamos da cláusula geral de responsabilidade prevista no parágrafo único do artigo 927. A doutrina, então, passou a se perguntar se seria aplicável a inovação do diploma civilista nos casos de acidente de trabalho, levando em conta a existência a previsão constitucional do tema. Em resposta a tal indagação surgiram diversas correntes.

Do ponto de vista de Sergio Cavalieri Filho (2005, p.188), a norma prescrita no Código Civil seria inaplicável aos casos de acidente de trabalho. Isso porque, diante do princípio da hierarquia normativa, uma norma infraconstitucional jamais poderia dispor em sentido oposto a Lei Maior. Assim, como a responsabilidade subjetiva do empregador em relação ao empregado pelo acidente de trabalho ou doença profissional já se encontra disciplinada no artigo 7ํㅜ, XXVIII da Constituição Federal, não haveria que se falar em aplicação da teoria objetiva nesses casos.

Ao enfrentar a controvérsia decorrente da aplicação do artigo 927 do Código Civil, Adib Pereira Netto Salim (2005, p.106) acredita na aplicabilidade de tal dispositivo. Isso seria possível porque a responsabilidade subjetiva do empregador prevista na Constituição Federal seria uma responsabilidade contratual, diante da imprescindibilidade de uma relação contratual de emprego, bem como em razão de tal prescrição constitucional inserir nos contratos de trabalho como cláusula obrigatória, integrando o chamado conteúdo mínimo dos contratos. Já a responsabilidade objetiva do empregador, alicerçada na teoria do risco criado, seria responsabilidade extracontratual, posto que se a atividade empresarial desenvolvida pelo empregador traz um risco inerente, ele responderá pelos danos causados a todos os lesados, inclusive aos seus empregados.

Não é ocioso relembrar que "o desenvolvimento da responsabilidade objetiva tem estreita ligação histórica com os acidentes do trabalho" (OLIVEIRA, 2005, p.92). Ademais, devemos ficar atentos aos princípios do Direito do Trabalho, em especial à regra da norma mais favorável, valorização do trabalho, bem como ao princípio constitucional da dignidade da pessoa humana. Sob esse prisma, acreditamos ser

Revista do Direito da UNISC, Santa Cruz do Sul, v.1, n. 45, p. 104-127, jan. - abri. 2015. 
compatível o diálogo entre aquilo previsto na Constituição Federal e o dispositivo do Código Civil.

É neste norte o entendimento de Juliane Caravieri Martins Gamba (2007, p.41-43). A autora afirma que não é sustentável uma interpretação literal do artigo $7^{\circ}$, inciso XXVIII da Carta Magna, pois ali estaria previsto apenas um rol mínimo de direitos fundamentais, deixando aberta a possibilidade da criação de outros direitos trabalhistas, ou ainda de serem melhorados aqueles já existentes, desde que observados os princípios e diretrizes previstos na Constituição Federal.

\section{DA TEORIA À PRÁTICA: ANÁLISE DO CONCEITO DE ATIVIDADE DE RISCO NAS DECISÕES JUDICIAIS}

O artigo 927 do Código Civil, ao dispor que "haverá obrigação de reparar o dano, independentemente de culpa, nos casos especificados em lei, ou quando a atividade normalmente desenvolvida pelo autor do dano implicar, por sua natureza, risco para os direitos de outrem" é considerado cláusula geral de responsabilidade. Observa-se que ele está de acordo com o novo paradigma surgido em meados do século XX, a partir da constatação de que uma norma positivada não seria capaz de abordar todas as necessidades humanas presentes e futuras. Assim é que tal dispositivo, se adequa a um sistema de cláusulas abertas ou gerais, alicerçados fundamentalmente na aplicação de princípios e tipos (PEDRO, 2011, p.72). Portanto, "adequando-se as leis aos fenômenos sociais concretas, pela utilização das cláusulas gerais, o judiciário preenche espaços em branco deixados no dispositivo, fixando, ato contínuo, a consequência da norma, integrando-a” (MELLO, 2010, p.14).

O dispositivo civilista não deixa claro o que se deve entender por "atividade normalmente desenvolvida", ou qual o sentido de "implicar, por sua natureza, risco". Veja-se que, por exemplo, que a expressão "independentemente de culpa" contida nesse dispositivo traz uma cláusula geral de responsabilidade objetiva com tamanha amplitude que, se interpretada literalmente, todos os que exercem alguma atividade passarão a responder objetivamente, tendo em vista que na sociedade atual praticamente todas as atividades implicam algum risco, e daí a necessidade de se examinar a real extensão dessa cláusula (CAVALIERI FILHO, 2005, p.181).

Revista do Direito da UNISC, Santa Cruz do Sul, v.1, n. 45, p. 104-127, jan. - abri. 2015. 
Muito embora tenha sido proposto o enunciado 38 da I Jornada de Direito Civil $^{2}$ visando melhor delinear os contornos do artigo 927 do Código Civil de 2002, inclusive deixando clara a adoção da teoria do risco criado, acreditamos que o citado artigo do diploma civil, dado seu grau de indeterminação, só poderá ser completamente compreendido quando da sua aplicação causuisticamente. Daí adequar-se perfeitamente ao denominado por Hart (2001, p.141) de "textura aberta do direito":

Seja qual for o processo escolhido, precedente ou legislação, para a comunicação de padrões de comportamento, estes não obstante a facilidade com que actuam sobre a grande massa de casos concorrentes, revelar-se-ão como indeterminados em certo ponto em que a sua aplicação esteja em questão; possuirão aquilo que foi designado como textura aberta. Até aqui, apresentámos tal, no caso da legislação, como um aspecto geral da linguagem humana; a incerteza na linha de fronteira é o preço que deve ser pago pelo uso de termos classificatórios gerais em qualquer forma de comunicação que respeite a questões de facto.

Nos filiamos a corrente que acredita na possibilidade de se aplicar a responsabilidade objetiva ao empregador que explora atividade econômica de risco. Todavia, os limites e a extensão dela devem ser dados na aplicação caso a caso, observando-se a presença do risco na atividade e todas as suas peculiaridades inerentes. Afinal, "todos nós que estamos vivos corremos riscos, entretanto, determinadas ocupações colocam o trabalhador num degrau de maior probabilidade de sofrer acidentes, em razão da natureza ou da periculosidade intrínseca da atividade" (OLIVEIRA, 2005, p.95). Evidentemente, temos que passar que resolução daquilo que se entende por "atividade econômica de risco", bem assim se isso pode ser uma definição rígida ou é flexível.

Embora seja verdade que viver, especialmente no mundo contemporâneo, é conviver os mais variados riscos, há determinadas atividades que expõem os indivíduos a uma periclitação que foge à normalidade, sendo ela criada pelas próprias peculiaridades da atividade econômica desenvolvida pelas empresas. Há atividades que naturalmente são perigosas e causam risco à saúde dos empregados, isso mesmo reconhecido pelo ordenamento jurídico, ao instituir

\footnotetext{
${ }^{2}$ Enunciado 38: A responsabilidade fundada no risco da atividade, como prevista na segunda parte do parágrafo único do artigo 927 do novo Código Civil, configura-se quando a atividade normalmente desenvolvida pelo autor do dano causar a pessoa determinada um ônus maior do que aos demais membros da coletividade.
}

Revista do Direito da UNISC, Santa Cruz do Sul, v.1, n. 45, p. 104-127, jan. - abri. 2015. 
aquelas situações, objetivamente consideradas, de pagamento do adicional de insalubridade e, mais agudamente, 0 de periculosidade (riscos inerentes à atividade). Noutro lado, há que se apontar que aquilo que não era arriscado pode vir a ser considerado de maneira diversa, pela própria dinâmica social, ou mesmo por uma guinada nos rumos da atividade normalmente desenvolvida pela empresa para explorar nichos do mercado em áreas territoriais ou condições distintas daquelas até então desenvolvidas, gerando condição perigosa aos empregados.

Aqui devemos notar duas situações claramente distintas. Uma, na qual o risco foi criado de fora, isto é, em decorrência das transformações naturalmente advindas do desenvolvimento social e econômico, a exemplo da escala da criminalidade. De outro lado, diverso é o panorama quando, por opção do empregador, ato interna corporis, as diretivas da exploração econômica são redirecionadas para algo que, sabidamente, potencialmente trará riscos para os empregados.

Portanto, a aquilo que se entende por "atividade normalmente desenvolvida" citada no parágrafo único do art. 927 do CCB acima citado, não representa um conceito fechado, ligado, no caso do direito do trabalho, apenas a um tipo determinado de ocupação. Há que se cotejar riscos que advém de uma decisão patronal em proceder sua atividade numa condição de risco acentuado, sendo crescente a ideia de explorar a origem e a motivação envolvidas no acidente.

Dessa maneira é que se justifica aprofundar nossa análise, à luz do que ocorre nos Tribunais. Isto porque ao examinar decisões proferidas pelas Cortes estamos diante da aplicação concreta e direta do direito, encarando-o como ele é e não como deveria ser. Ainda cumpre mencionar que como os juízes ou ministros não são apenas meros aplicadores do direito, ou "máquinas de aplicar as leis" mas sim intérpretes delas, os julgadores e, principalmente, os tribunais, frente a um problema proposto pelas partes, ao decidirem, acabam por sugerir, ou até mesmo criar para os seus pares, um caminho a trilhar.

A título de ilustração de como ainda é atual a controvérsia na aplicação da responsabilidade objetiva ou subjetiva nas cortes laborais, especialmente pela indeterminação do conceito de atividade normalmente desenvolvida com risco, selecionamos dois acórdãos proferidos pela primeira e segunda turma do Tribunal Regional do Trabalho da 13 $3^{a}$ Região (TRT 13). Não é ocioso que ambos foram publicados no mês de agosto do ano de 2013 , tendo como parte reclamada a 
Empresa Brasileira de Correios e Telégrafos (ECT), conforme ementas abaixo transcritas:

\begin{abstract}
ASSALTO. DANOS MORAIS. INEXISTÊNCIA DE ATO ILÍCITO. INDENIZAÇÃO $\quad$ INDEVIDA.

No âmbito do Direito do Trabalho, a indenização por danos morais só é devida se coexistirem o nexo causal e o dolo ou culpa do empregador, consoante expressa disposição constitucional nesse sentido. Não demonstrada atitude ilícita da demandada a ensejar ou concorrer para a ocorrência do evento danoso, não há como se the imputar nenhuma obrigação indenizatória. (TRT 13; RO 0073200-26.2012.5.13.0004; Primeira Turma; Desembargadora Relatora Ana Maria Ferreira Madruga, Data da publicação: 07/08/2013)
\end{abstract}

\title{
RECURSO ORDINÁRIO. BANCO POSTAL. DANOS MORAIS.RESPONSABILIDADE OBJETIVA DO EMPREGADOR.
} Via de regra, a responsabilidade do empregador é subjetiva, fazendo-se necessária a comprovação de dolo ou culpa para imputação do ônus por danos sofridos por seus funcionários, a teor da CF/1988, art. $7^{\circ}$, XXVIII, in fine . Ocorre que a Carta Magna estabelece os direitos mínimos dos trabalhadores, mas não tem efeito paralisante sobre a concessão de outros benefícios aos empregados. Nesse contexto, o novo CC, art. 927, trouxe inovação ao ordenamento jurídico, ao admitir a responsabilização do agente, independentemente de culpa, quando a natureza da atividade desenvolvida implique risco para terceiros. Nesse sentido, as regras de experiência comum apontam que as agências bancárias, e aqui incluindo-se os correspondentes postais, são alguns dos mais frequentes alvos de assaltos. Infelizmente, não se trata mais de fato imprevisível, nem de evento estranho à dinâmica da labuta dos trabalhadores que atuam nestes meios. Reafirme-se que a segurança pública não é apenas dever do Estado, mas sim responsabilidade de todos (CF, art. 144) - máxime da reclamada, desde de que se pôs a atuar como correspondente bancária. Responsabilidade objetiva do empregador reconhecida, para se manter a condenação ao pagamento de indenização por danos morais.

(TRT 13; RO 0101200-39.2012.5.13.0003; Segunda Turma; Juiz Relator Convocado Normando Salomão Leitão, Data da publicação: 22/08/2013)

Observe-se que enquanto no primeiro acórdão o entendimento foi de considerar indevida a indenização pleiteada pelo reclamante à luz da teoria da responsabilidade subjetiva, o segundo entendeu pela aplicação da teoria objetiva da responsabilidade do empregador. Diante de decisões diametralmente opostas, acreditamos ser necessário proceder à análise da hipótese dos autos, bem como dos argumentos utilizados em cada julgado proferido pela Corte Regional.

Revista do Direito da UNISC, Santa Cruz do Sul, v.1, n. 45, p. 104-127, jan. - abri. 2015. 
Os empregados, em ambos os casos operadores de caixa, pleiteavam indenizações de cunho material e moral, alegando que estariam sofrendo com distúrbios psicológicos decorrentes de assaltos ocorridos nas agências postais da ECT. Aduziam também que os Correios não estariam cumprindo com o dever de segurança, eis que na situação de correspondentes bancários (bancos postais), não estariam cumprindo com todas as medidas de segurança necessárias ao desenvolvimento das suas atividades, como porta giratória e vigilantes armados, nos termos da Lei Federal no $7.102 / 83^{3}$.

É importante fazer aqui uma pequena digressão, antes de procedermos a análise das razões e argumentos de cada acórdão. Ressaltamos que, diante da dicção legal do artigo 21, inciso II, letra "a" da Lei 8.213/91, os danos causados a um empregado, por força de assalto a banco postal, configuram acidente de trabalho.

$\mathrm{Na}$ reclamação trabalhista tombada sob o número 0073200 26.2012.5.13.0004, o Regional firmou posicionamento de que a Lei 7.102/83, destina-se exclusivamente a estabelecimentos financeiros. Dessa forma, embora a ECT atuasse também como correspondente bancário, sua atuação era limitada, tendo em vista haver restrição de limites quanto aos valores que nelas tramitam bem inferiores aos de uma agência bancária. Então, por possuir um sistema de alarme, botão do pânico e sistema de webcam, teria se desincumbido do dever geral de cautela para com o seus empregados, sendo a segurança pública dever do Estado. Ressaltou ainda que a correspondência bancária não se enquadraria como atividade principal dos Correios. Finalmente, conclui pela improcedência do pleito obreiro, sob o prisma da responsabilização subjetiva, ainda que constatado o nexo causal entre a patologia do reclamante e a função desempenhada pelo mesmo, frente a inexistência de qualquer ato ilícito praticado pela empresa e principalmente considerando que o assalto é um fato de terceiro, sob o qual não teria a ECT qualquer domínio.

\footnotetext{
${ }^{3}$ Art. 2o da Lei 7.102/83 - O sistema de segurança referido no artigo anterior inclui pessoas adequadamente preparadas, assim chamadas vigilantes; alarme capaz de permitir com segurança, comunicação entre o estabelecimento financeiro e outro da mesma instituição, empresa de vigilância ou órgão policial mais próximo; e pelo menos, mais um dos seguintes dispositivos: I- Equipamentos elétricos, eletrônicos e de filmagens que possibilitem a identificação dos assaltantes; II- Artefatos que retardem a ação dos criminosos, permitindo sua perseguição, identificação ou captura; e III- Cabina blindada com permanência ininterrupta de vigilante durante o expediente para o público e enquanto houver movimentação de numerário no interior do estabelecimento.
}

Revista do Direito da UNISC, Santa Cruz do Sul, v.1, n. 45, p. 104-127, jan. - abri. 2015. 
Em sentido contrário decidiu o TRT 13 na ação trabalhista de número 0101200-39.2012.5.13.0003. Veja-se que o cerne da questão residiria na existência ou não de responsabilidade patronal por danos suportados pelo empregado, em consequência de fato de terceiro. Utilizando-se do argumento da primazia da realidade, e em uma interpretação extensiva, entendeu-se que o conceito de agência bancária abarcaria 0 de correspondentes postais, caso da ECT, reconhecendo-se que ambos estariam sujeitos a assaltos constantes, não podendo esses serem mais considerados como imprevisíveis ou estranhos a dinâmica laboral. Assim, deveria ser aplicado o previsto na Lei 7.102/83 quanto as medidas de segurança, especialmente levando em conta ser repartida entre Estado e civis o dever da garantia da segurança pública. Dessa maneira, os Correios não teriam preenchido todos os requisitos necessários à garantia de segurança de seus empregados. Por fim, a Turma decidiu pela aplicação da teoria objetiva da responsabilidade civil, pois caracterizado o nexo causal entre o dano e as funções desempenhadas, especificando que não caberia ao obreiro assumir os riscos do empreendimento e sim ao empregador.

Transpondo a questão para o âmbito do Tribunal Superior do Trabalho, já há julgados sinalizando a aplicação da teoria do risco criado em casos similares. Vejamos:

INDENIZAÇÃO POR DANO MORAL. ECT. BANCO POSTAL. ATIVIDADE BANCÁRIA PROPRIAMENTE DITA. ASSALTO SOFRIDO PELA RECLAMANTE NAS DEPENDÊNCIAS DA RECLAMADA. CONFIGURAÇÃO. Discute-se, nos autos, pedido de indenização por dano moral formulado por empregado de Banco Postal da ECT que foi vítima de assaltos nas dependências desse estabelecimento, o que lhe ocasionou um estresse pós-traumático. De acordo com o Regional, é incontroverso que o reclamante foi vítima de seis assaltos ocorridos à mão armada em seu local de trabalho enquanto desenvolvia suas atividades profissionais. Registrou, ainda, que a reclamada, ao iniciar a prestação de serviços tipicamente bancários, passou a exercer uma atividade de risco, capaz, potencialmente, de causar dano e, além disso, foi omissa na obrigação de assegurar a integridade física e a segurança dos seus empregados. Diante desse quadro fático, concluiu que a reclamada concorreu culposamente para o incidente havido, devendo ser responsabilizada pelos danos sofridos pela vítima, à luz do disposto no artigo 927 do Código Civil. Em que pese a questão da ausência de segurança pública resultar, atualmente, em risco no exercício de qualquer atividade laboral, tratando-se de empregados que desenvolvem atividades bancárias, quer em bancos propriamente ditos, quer em entidades aos bancos equiparadas, como no caso dos autos, não se pode olvidar que

Revista do Direito da UNISC, Santa Cruz do Sul, v.1, n. 45, p. 104-127, jan. - abri. 2015. 
estão mais sujeitos a riscos de assaltos, assim como o ocorrido, conforme demonstram as estatísticas, que registram, muitas vezes, até mesmo sequestros de empregados e de suas famílias. Observa-se, na hipótese, que não há no acórdão regional nenhuma menção ao fato de a reclamada ter adotado alguma medida de segurança capaz de minimizar os riscos inerentes à sua atividade, o que implica, portanto, culpa por omissão. Dessa forma, estando presentes o dano moral, inequívoco nos autos, consistente no sofrimento emocional a que o autor foi submetido, o nexo de causalidade e a culpa do empregador, nasce a obrigação de indenizar. Recurso de revista não conhecido. [...]

(RR - 792-40.2010.5.18.0013, Relator Ministro: José Roberto Freire Pimenta, Data de Julgamento: 27/11/2013, 2a ${ }^{\text {a }}$ Turma, Data de Publicação: DEJT 06/12/2013, grifamos)

Indo ainda um pouco além, igualmente no âmbito da maior Corte Trabalhista ainda vamos encontrar sinais evidentes dessa migração, a exemplo daquilo que se transcreve a seguir:

\begin{abstract}
RECURSO DE EMBARGOS. TÉCNICO EM INFORMÁTICA. EXERCÍCIO DE ATIVIDADE EM RODOVIAS INTERMUNICIPAIS. ATIVIDADE DE RISCO.ACIDENTE DE TRABALHO EM VEÍCULO AUTOMOTOR COM EVENTO MORTE. CULPA EXCLUSIVA DE TERCEIRO. Embora hoje haja verdadeira controvérsia na doutrina e na jurisprudência com o fim de afastar a responsabilidade do empregador, por fato de terceiro, ainda que em atividade de risco, a matéria merece uma reflexão mais cuidadosa, na medida em que tal afastamento decorre da possibilidade de o autor vir a ajuizar ação de regresso ao terceiro, causador do dano. Tal entendimento, todavia, no direito do trabalho, não pode ser recepcionado, quando é certo que a responsabilidade pela atividade econômica é do empregador, e não do empregado. A leitura a ser feita da norma inscrita no art. $2^{\circ}$ da CLT c/c art. 927, parágrafo único, do CC, em conjunção com os princípios que regem a relação jurídica trabalhista, é no sentido de que a indenização é devida ao empregado e que eventual ação de regresso, a ser intentada, deverá ser feita pelo empregador, contra aquele cuja conduta ensejou a sua responsabilidade na reparação do dano. Recurso de embargos conhecido e desprovido.

(E-RR - 1299000-69.2008.5.09.0016, Relator Ministro: Aloysio Corrêa da Veiga, Data de Julgamento: 16/02/2012, Subseção I Especializada em Dissídios Individuais, Data de Publicação: 13/04/2012, grifamos).
\end{abstract}

Os sintomas jurisprudenciais são claríssimos a apontar que a condição de risco não é inerente à atividade, isoladamente considerada do contexto espaçotemporal, constituindo em autêntico conceito "em branco", a ser integrado por aquilo que efetivamente se extrai do caso levado a julgamento, pois, isoladamente considerada, a atividade de um técnico de informática não poderia ser tipificada como de risco inerente, ele surge a partir de uma prática levada a efeito pela

Revista do Direito da UNISC, Santa Cruz do Sul, v.1, n. 45, p. 104-127, jan. - abri. 2015. 
maneira como o empregador, gestor dos elementos produtivos, coloca a força de trabalho nesta ou naquela contingência.

Sob tal prisma, qualquer empregador, mesmo os entes estatais, se estiverem explorando atividade econômica, seja na modalidade concorrencial ou exercendo prática monopolística (como é o caso da ECT, por exemplo), caso opte por exercer determinada atividade que acentue o risco normalmente existente nas atividades desenvolvidas por seus empregados, estará sujeita à responsabilização objetiva. $E$ aqui não há que se confundir com qualquer modalidade de culpa em sentido estrito, a partir da constatação de que não se trata de um caso isolado, ou com impacto contido num grupo pequeno de empregados, mas estamos falando de uma prática patronal que sinaliza uma opção por alterar o pertencimento econômico da empresa, explorando áreas com grau de risco para os seus empregados.

O problema dessa indeterminação e incompletude conceitual reside na mitigação da segurança jurídica, especialmente diante da larga moldura discricionária na tomada das decisões que versam sobre responsabilidade civil do empregador. No entanto, a crítica perde força quando percebemos que tudo aquilo que estamos advogando nada mais é que a aplicação do princípio na inalterabilidade contratual, do pacta sunt servanda. Há muito que a CLT veda alterações contratuais por parte dos empregadores que sejam lesivas, direta ou indiretamente, aos empregados (art. 468), cominando de nulidade tais mutações. Evidentemente, na impossibilidade de se promover plenamente a restituição integral, dada a gravidade dos danos, o caminho é a resolução por perdas e danos, aplicando-se o caminho bem mais simplificado, no campo probatório, da responsabilidade objetiva, que prescinde da caracterização da culpa.

\section{CONSIDERAÇÕES FINAIS}

O direito é dinâmico e como tal deve adaptar-se a novas realidades sociais, que se transformam cada vez mais rapidamente. Diante dos anseios sociais por justiça e reparação efetiva de danos, notadamente frente ao grande número de acidentes de trabalho é que a ideia de uma responsabilidade civil eminentemente subjetiva, em que se obriga a vítima ao pesado ônus de demonstrar no judiciário o prejuízo sofrido, o nexo causal, ação ou omissão voluntária, e a comprovação de

Revista do Direito da UNISC, Santa Cruz do Sul, v.1, n. 45, p. 104-127, jan. - abri. 2015. 
uma conduta dolosa, imprudente ou negligente da outra parte, não mais se justifica para toda e qualquer situação. Assim é que o ordenamento jurídico brasileiro, através do seu Código Civil de 2002 passa a prever a possibilidade da responsabilização objetiva, fundamentada na teoria do risco, que cada vez mais ganha aceitação na jurisprudência.

Nas relações de trabalho, a concepção do dever de indenizar, refletida no artigo $7^{0}$ da Constituição Federal, está intrinsecamente atrelada à falta de cuidado patronal no cumprimento de normas de segurança, higiene ou saúde de seus empregados, acarretando assim, acidente ou doença ocupacional. Veja-se que 12 anos depois da entrada em vigor do Novo Código Civil, os limites e a abrangência da aplicação da responsabilidade objetiva ainda são questões controversas e problemáticas.

Com efeito, a responsabilidade objetiva ainda não pode ser transformada em regra geral, dada sua indeterminação legal, decorrente da textura aberta do parágrafo único do artigo 927 do diploma civil, eis que conforme pudemos comprovar, ela gera decisões diametralmente opostas, notadamente na Justiça do Trabalho. Como resultado dessa indeterminação e incompletude conceitual incorremos no campo da insegurança jurídica, especialmente diante da ampla moldura discricionária na tomada das decisões que versam sobre responsabilidade civil do empregador.

É bem verdade que temos que emprestar um sentido restritivo aquilo se entende por atividade normalmente desenvolvida pela empresa com vistas à incidência da teoria do risco criado, sob pena de implantarmos custos excessivos à exploração econômica, dificultando até mesmo o desenvolvimento de determinados segmentos econômico-sociais. Contudo, isso não pode ser feito situando-o tão só naquilo que seria o pertencimento econômico da empresa, como atividades que envolvam operações insalubres, perigosas, ou mesmo que possam carrear riscos expressivos de acidentes do trabalho, conforme estatísticas do próprio Ministério do Trabalho, à exemplo da construção civil. Vimos que o próprio empregador pode assumir uma condição de risco para seus empregados, motivado pela expansão de suas atividades, algo que, pela alteridade, irá carrear para si os ônus daí decorrentes, particularmente a responsabilidade objetiva em havendo acidentes do trabalho, por danos morais e patrimoniais. Existem, pois, parâmetros que vão se 
estabelecendo pela atividade jurisprudencial, que vão moldando a aplicação desse tipo de responsabilidade, evitando sua disseminação indiscriminada.

Por outro lado, para aqueles empregadores que estão situados fora do contexto da exploração econômica, a regra geral seria a responsabilidade subjetiva, dado que a ausência da finalidade lucrativa e da assunção dos riscos inerentes a isso cria uma situação desfavorável à implantação da teoria do risco criado.

Pensar de outra maneira, ampliando demasiadamente o sentido daquela expressão legal, implicaria na responsabilização do empregador por fatos que não são inerentes a sua atividade econômica, tais como a inserção de uma empresa em área sujeita a assaltos, transferindo, então, para o empregador os ônus decorrentes da inércia do poder público em fornecer segurança a seus cidadãos. Nesse caso, a única maneira de se imputar ao empregador algum tipo de condenação decorreria do fato deste ter inserido sua empresa deliberadamente em local de risco, ao contrário, da empresa ter sido instalada em local que aparentemente não traria nenhum perigo para seus empregados e dada a escalada da violência, os trabalhadores passaram a se sujeitar aos constrangimentos decorrentes.

\section{REFERÊNCIAS}

BRASIL. Tribunal Superior do Trabalho. Recurso de revista 79240.2010.5.18.0013. Data de publicação no diário da justiça do trabalho 06/12/2013.

. Embargos em recurso de revista 1299000-69.2008.5.09.0016. Data de Publicação no diário da justiça do trabalho: 13/04/2012

CAMPINHO, Sérgio. O direito de empresa à luz do novo Código Civil. 10ed. São Paulo: Renovar, 2009.

CARDOZO, Benjamin Natan. Evolução do direito. Belo Horizonte: Lider, 2004.

CAVALIERI FILHO, Sergio. Programa de Responsabilidade Civil. 6ª̂ed. São

Paulo: Malheiros editores Ltda, 2005.

DELGADO, Maurício Godinho. Curso de Direito do Trabalho. 2ed. São Paulo: LTr, 2003.

GAMBA, Juliane Caravieri Martins. Responsabilidade civil objetiva pelos danos à saúde do trabalhador. Semina: Ciências Sociais e Humanas. Londrina, v. 28, n.1, p. 23-44, jan./jun. 2007. Disponível em:

Revista do Direito da UNISC, Santa Cruz do Sul, v.1, n. 45, p. 104-127, jan. - abri. 2015. 
http://www.uel.br/revistas/uel/index.php/seminasoc/article/viewFile/3772/3031.

Acesso em: 03/02/2014

HART, Herbert L.A. O conceito de direito. $3^{\text {a }}$ ed. Lisboa: Fundação Calouste Gulbenkian, 2001.

MAGANO, Octávio Bueno. Direito Individual do Trabalho. 4 ed. 2v. São Paulo: LTr, 1993.

MELLO, Glaucia Rodrigues Torres de Oliveira. A cláusula geral de responsabilidade civil objetiva no código civil. Revista de direito dos monitores da Universidade Federal Fluminense. Rio de Janeiro, ano 3, n.8, p.2-24, maio-agosto 2010. Disponível em: http://www.rdm.uff.br/inzzdex.php/rdm/article/view/93/0. Acesso em 03/02/2014

OLIVEIRA, Sebastião Geraldo de. Indenizações por acidente do trabalho ou doença ocupacional. São Paulo: Ltr, 2005

PARAÍBA. Tribunal Regional do Trabalho da 13롤 Região. Recurso ordinário 0073200-26.2012.5.13.0004; publicado no diário da justiça em: 07/08/2013.

Recurso ordinário 0101200-39.2012.5.13.0003. Data da publicação no diário da justiça 22/08/2013

PEDRO, Fábio Anderson de Freitas. A socialização da responsabilidade civil: a evolução do subjetivo liberal ao objetivo-social. Revista da SJRJ. Rio de Janeiro, v.18, n.32, p.65-77, dez 2011.Disponível em:

http://www4.jfri.jus.br/seer/index.php/revista siri/article/viewFile/277/260. Acesso em: 03/02/2014

SALIM, Adib Pereira Netto. A teoria do risco criado e a responsabilidade objetiva do empregador em acidentes de trabalho. Revista do Tribunal Regional do Trabalho

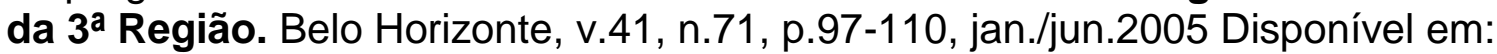
http://www.trt3.jus.br/escola/download/revista/rev 71/Adib Salim.pdf. Acesso em 30/01/2014.

SÜSSEKIND, Arnaldo et. al. Instituições de Direito do Trabalho. 16 ed. 2v. São Paulo: Ltr, 1996.

VENOSA, Silvio de Salvo. Direito civil. 5ํㅡㄹ. ed. São Paulo: Atlas, 2005.

Revista do Direito da UNISC, Santa Cruz do Sul, v.1, n. 45, p. 104-127, jan. - abri. 2015. 